\title{
THE P WAVE IN ATRIAL SEPTAL DEFECT
}

\author{
BY \\ A. SÁNCHEZ-CASCOS* AND DENNIS DEUCHAR \\ From the Cardiac Department, Guy's Hospital, London S.E.I
}

Received July 2, 1962

In 1952 Cabrera and Monroy developed the concept of systolic and diastolic overloading of the ventricles and correlated the type of overloading with the resulting pattern in the electrocardiogram. By systolic overload is meant the situation where the ventricle handles a normal or reduced stroke volume but has to eject it against increased resistance: by diastolic overload is meant the situation where the ventricle receives more than the normal diastolic filling but the resistance to ejection is normal. The term systolo-diastolic overload has been used for the situation where both diastolic filling and the resistance to ejection are increased.

In 1959 Sánchez-Cascos, Sokolowski, and Rábago in the course of an analysis of the $\mathrm{P}$ wave in cases of atrial septal defect recognized a pattern of $P$ wave abnormality not hitherto described. This pattern was characterized by a $\mathrm{P}$ wave of normal height but of increased width and with a prolonged duration of the upstroke. This pattern contrasted with the generally recognized pattern of right atrial hypertrophy, the so-called pulmonary or congenital P (Zuckerman et al., 1952). This latter type of $P$ wave is typically narrow and tall, with a rapid upstroke. It was postulated that this latter pattern reflected systolic overloading of the right atrium whereas the newly recognized pattern reflected diastolic overloading of the atrium. The two patterns were found to be combined in some cases of atrial septal defect with increased pulmonary arterial resistance, and appeared to represent systolo-diastolic overloading of the right atrium (Sánchez-Cascos, 1960).

Although the $P$ wave in atrial septal defect has been analysed by a number of workers, it appears that so far only Hamer (1960) has studied this aspect, and his series consists of only 18 cases. Likewise the original series studied by Sánchez-Cascos consisted of only a few cases and the material was not sufficient for statistical analysis.

This paper reports the results of a further study of the $P$ wave in 106 cases of proved atrial septal defect, conducted to see if the original observations could be substantiated in a larger series capable of statistical analysis.

\section{SubJECTS AND MeThodS}

The electrocardiograms from 122 patients with atrial septal defect (ASD) have been examined; of these 12 showed atrial fibrillation, 2 atrial flutter, and 2 ectopic rhythms, and these 16 were discarded, leaving 106 for analysis. Of these, 90 came from the Cardiac Department of Guy's Hospital, London, and 16 from the Institute for Medical Research, Madrid. In all these patients catheterization showed a left-to-right shunt at atrial level. In 54 the diagnosis was also confirmed at operation. In 84 the septal defect was of the ostium secundum or sinus venosus type, and in 22 of the ostium primum type. These two groups have been analysed separately owing to the possible complication of atrioventricular valve incompetence in the latter: for simplicity the larger group, although including examples of the sinus venosus defect, will hereafter be referred to as the ostium secundum group.

In every case a routine 12-lead cardiogram was available and venous catheterization was performed to obtain the right heart pressures and the data necessary for the calculation of the size of the shunt. Blood

* In receipt of a British Council Scholarship. 
flows were estimated by means of the Fick principle; oxygen consumption was measured by spirometry during the catheterization procedure; and the blood samples were analysed either by the Haldane technique or by a spectrophotometric method. In nearly all cases the electrocardiograms were recorded by a Sanborn cardiograph, direct-writing with a heated stylus. Measurements were made by direct inspection, and occasionally a hand lens was used. The width, height, and upstroke time of the P wave in lead II (PII) were measured; and where the $P$ wave was bifid the time of the second peak was also measured. The form of $P$ in $\mathrm{V} 1$ was also noted. Where there appeared to be some variation in the parameter of the $\mathbf{P}$ wave the mean of five or more cycles was obtained. Time intervals are expressed in seconds and the heights in $\mathrm{mm} .(1 \mathrm{~mm} .=0 \cdot 1$ $\mathrm{mV})$.

These electrocardiographic measurements from the 84 examples of ostium secundum ASD were correlated with the following hæmodynamic ones: systolic pressure in the right atrium (RA), left atrium (LA) (if entered through the atrial defect or as measured in the pulmonary arterial wedge position), and right ventricle (RV) expressed in $\mathrm{mm}$. $\mathrm{Hg}$ from the mid-axillary line in the supine subject, and the magnitude of the left-to-right interatrial shunt expressed as a percentage of the pulmonary blood flow $(50 \%=2: 1$ flow ratio and $75 \%=4: 1$ ratio). This analysis was not applied to the ostium primum group as the numbers were small and because of the higher incidence of complicating features (e.g. mitral regurgitation, pulmonary hypertension) in this group.

In 17 patients with an ostium secundum ASD a record obtained a year or more after closure of the defect was studied and compared with the pre-operative record. In addition, the electrocardiograms of 20 normal medical students and nurses at Guy's Hospital, of 75 patients with pulmonary stenosis (PS), and of 4 patients with pulmonary stenosis and ASD were studied for comparison.

\section{RESULTS}

The values of the parameters of PII in the different groups are given in Table I. It is apparent that the mean values for all the parameters of PII are higher in the groups with ASD than in the normal controls. The difference in upstroke time is particularly noteworthy: in the normal controls

TABLE I

PARAMETERS OF PII

\begin{tabular}{|c|c|c|c|c|c|c|}
\hline & & No. & Height (mm.) & Width (sec.) & $\begin{array}{l}\text { Upstroke time } \\
\text { (sec.) }\end{array}$ & 2nd peak \\
\hline & & & \multirow{6}{*}{\multicolumn{2}{|c|}{\begin{tabular}{c|c}
\multicolumn{2}{c}{ Means and standard deviation } \\
1.2 & 0.083 \\
$( \pm 0 \cdot 4)$ & $( \pm 0.016)$ \\
1.8 & 0.097 \\
$( \pm 0 \cdot 8)$ & $( \pm 0.013)$ \\
2 & $0 \cdot 10$ \\
$( \pm 0 \cdot 8)$ & $( \pm 0.017)$ \\
$2 \cdot 3$ & 0.078 \\
$( \pm 1 \cdot 1)$ & $( \pm 0.016)$ \\
$5 \cdot 2$ & $0 \cdot 10$ \\
$(-)$ & $(-)$
\end{tabular}}} & \multirow{6}{*}{$\begin{array}{c}0.03 \\
( \pm 0.009) \\
0.059 \\
( \pm 0.011) \\
0.05 \\
( \pm 0.012) \\
0.035 \\
( \pm 0.008) \\
0.045 \\
(-)\end{array}$} & \\
\hline Normal & . & 20 & & & & $9(45 \%)$ \\
\hline OS $\quad$. & .. & 84 & & & & $12(14 \%)$ \\
\hline OP &.. & 22 & & & & $11(50 \%)$ \\
\hline PS $\quad$. & . & 73 & & & & $8(11 \%)$ \\
\hline PS + ASD & .. & 4 & & & & $\underline{0}$ \\
\hline
\end{tabular}

$\mathrm{OS}=$ ostium secundum group. $\quad \mathrm{OP}=$ ostium primum group.

$\mathrm{PS}=$ pulmonary stenosis series. $\mathrm{PS}+\mathrm{ASD}=$ group with combined lesions.

this did not exceed $0.04 \mathrm{sec}$. but in the majority of the patients it did so (Table II). There is little difference between the two groups of ASD apart from the much lower incidence $(14 \%)$ of a second peak in the ostium secundum group as compared with 50 per cent in the ostium primum group. By contrast the pulmonary stenosis patients do not differ significantly from the normal controls except in respect of the height of the wave. In the four patients with the combination of PS and ASD the principal abnormality was the height of PII: all these patients had very high RV systolic pressures and had no left-to-right shunt.

An examination of the correlation between the hæmodynamic values and the $P$ wave parameters in the ostium secundum showed no relation between the width of PII and the systolic pressures 
TABLE II

Distribution of Patients According to Upstroke Time

\begin{tabular}{|c|c|c|c|c|c|c|c|c|c|}
\hline \multirow{2}{*}{\multicolumn{2}{|c|}{ Group }} & \multicolumn{7}{|c|}{ Upstroke time (sec.) } & \multirow{2}{*}{ Total } \\
\hline & & 0.02 & 0.03 & 0.04 & 0.05 & 0.06 & 0.07 & 0.08 & \\
\hline $\begin{array}{l}\text { Normal } \\
\text { OS .. } \\
\text { OP } \\
\text { PS ... } \\
\text { PS + ASD }\end{array}$ & $\begin{array}{l}\ldots \\
\ldots \\
\ldots \\
\ldots \\
\ldots\end{array}$ & $\begin{array}{l}7 \\
0 \\
0 \\
8 \\
0\end{array}$ & $\begin{array}{r}4 \\
0 \\
1 \\
23 \\
2\end{array}$ & $\begin{array}{r}9 \\
11 \\
5 \\
39 \\
0\end{array}$ & $\begin{array}{r}0 \\
21 \\
10 \\
3 \\
0\end{array}$ & $\begin{array}{r}0 \\
26 \\
4 \\
0 \\
2\end{array}$ & $\begin{array}{r}0 \\
19 \\
0 \\
0 \\
0\end{array}$ & $\begin{array}{l}0 \\
7 \\
2 \\
0 \\
0\end{array}$ & $\begin{array}{r}20 \\
84 \\
22 \\
73 \\
4\end{array}$ \\
\hline
\end{tabular}

Abbreviations as in Table I.

TABLE III

Ostium Secundum Group

Mean Hamodynamic Values According to the Width of PII

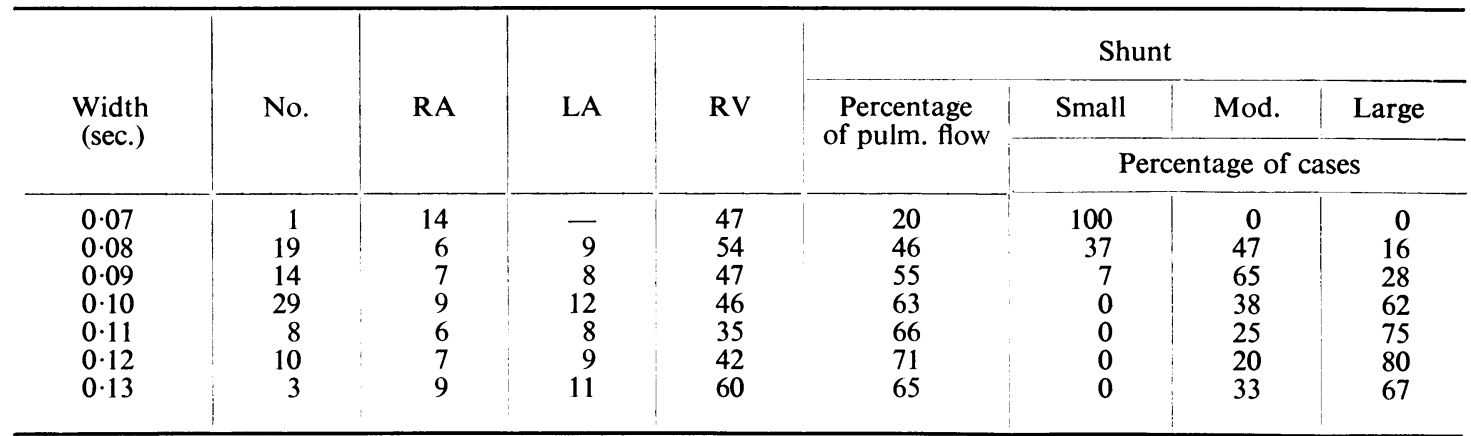

$\mathrm{RA}, \mathrm{LA}$, and $\mathrm{RV}=$ systolic pressures in right atrium, left atrium, and right ventricle in $\mathrm{mm} . \mathrm{Hg}$. Shunts: small is less than 40 per cent of the pulmonary blood flow, moderate is between 40 and 60 per cent, and large is greater than 60 per cent.

in the right heart chambers or left atrium (Table III). There is, however, a significant correlation between this width and the size of the shunt: this is shown graphically in Fig. 1. The coefficient of correlation was $0.7(\mathrm{p}<0.0001)$. The same situation exists in relation to the upstroke time of PII (Table IV): there is no relation between the time and the systolic pressures but again there is a significant correlation between it and the size of the shunt (Fig. 2), the coefficient of correlation being $0.6(\mathrm{p}<0.0001)$. The product of the width and upstroke time, both expressed as hundredths of a

TABLE IV

Ostium Secundum Group

Mean Hemodynamic Values According to Upstroke Time of PII

\begin{tabular}{|c|c|c|c|c|c|c|c|c|}
\hline \multirow{3}{*}{$\begin{array}{l}\text { Time } \\
\text { (sec.) }\end{array}$} & \multirow{3}{*}{ No. } & \multirow{3}{*}{$\mathrm{RA}$} & \multirow{3}{*}{ LA } & \multirow{3}{*}{ RV } & \multicolumn{4}{|c|}{ Shunt } \\
\hline & & & & & \multirow{2}{*}{$\begin{array}{l}\text { Percentage } \\
\text { of pulm. flow }\end{array}$} & Small & Mod. & Large \\
\hline & & & & & & \multicolumn{3}{|c|}{ Percentage of cases } \\
\hline $\begin{array}{l}0.04 \\
0.05 \\
0.06 \\
0.07 \\
0.08\end{array}$ & $\begin{array}{r}11 \\
21 \\
26 \\
19 \\
7\end{array}$ & $\begin{array}{l}6 \cdot 5 \\
7 \cdot 7 \\
7 \cdot 6 \\
8 \\
4\end{array}$ & $\begin{array}{r}10 \\
8 \\
11 \\
10 \\
7\end{array}$ & $\begin{array}{l}44 \\
47 \\
46 \\
44 \\
36\end{array}$ & $\begin{array}{l}45 \\
54 \\
60 \\
65 \\
73\end{array}$ & $\begin{array}{r}55 \\
15 \\
0 \\
0 \\
0\end{array}$ & $\begin{array}{r}18 \\
52 \\
57 \\
32 \\
0\end{array}$ & $\begin{array}{r}27 \\
33 \\
43 \\
68 \\
100\end{array}$ \\
\hline
\end{tabular}

Abbreviations as in Table III. 


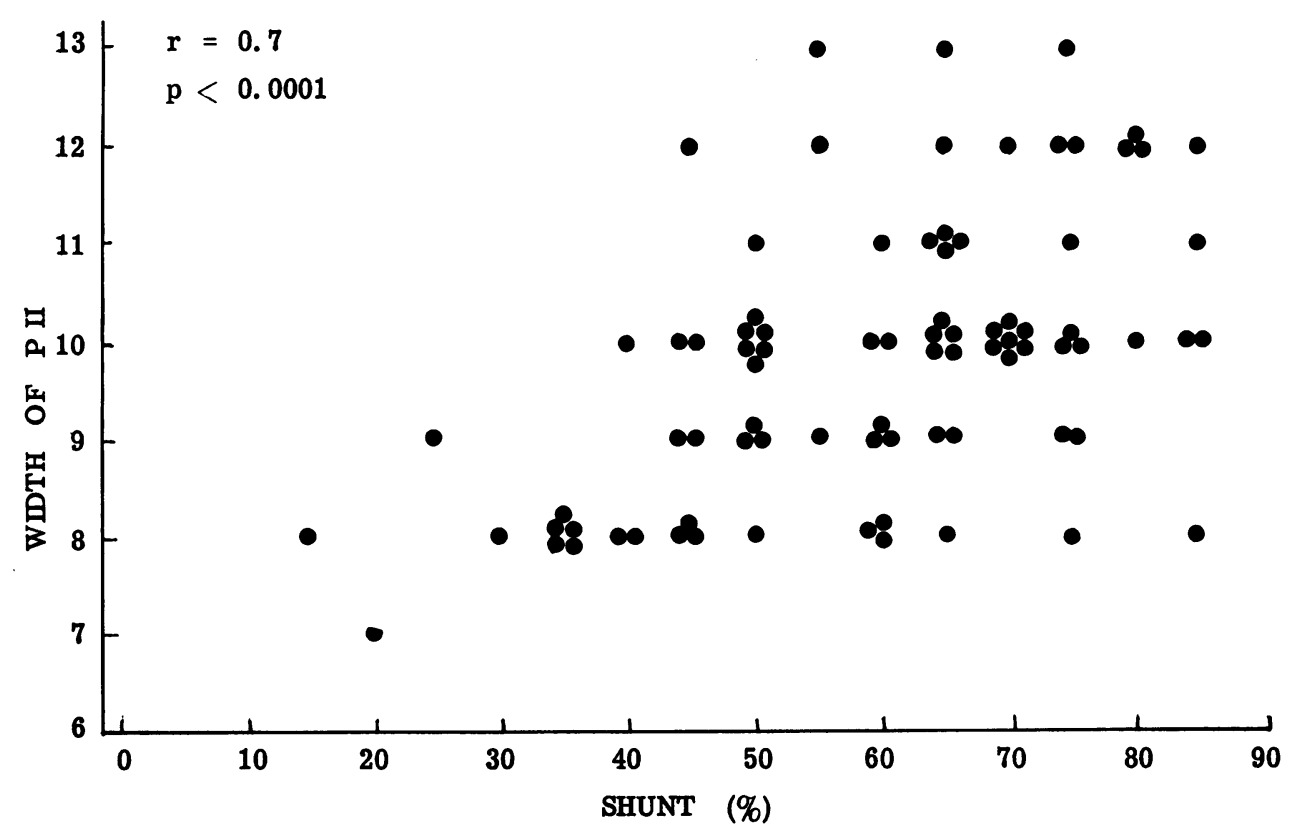

FIG. 1.-The widths of PII in hundredths of a second in the 84 cases of the ostium secundum group, plotted against the volume of the shunt, expressed as a percentage of the pulmonary flow.

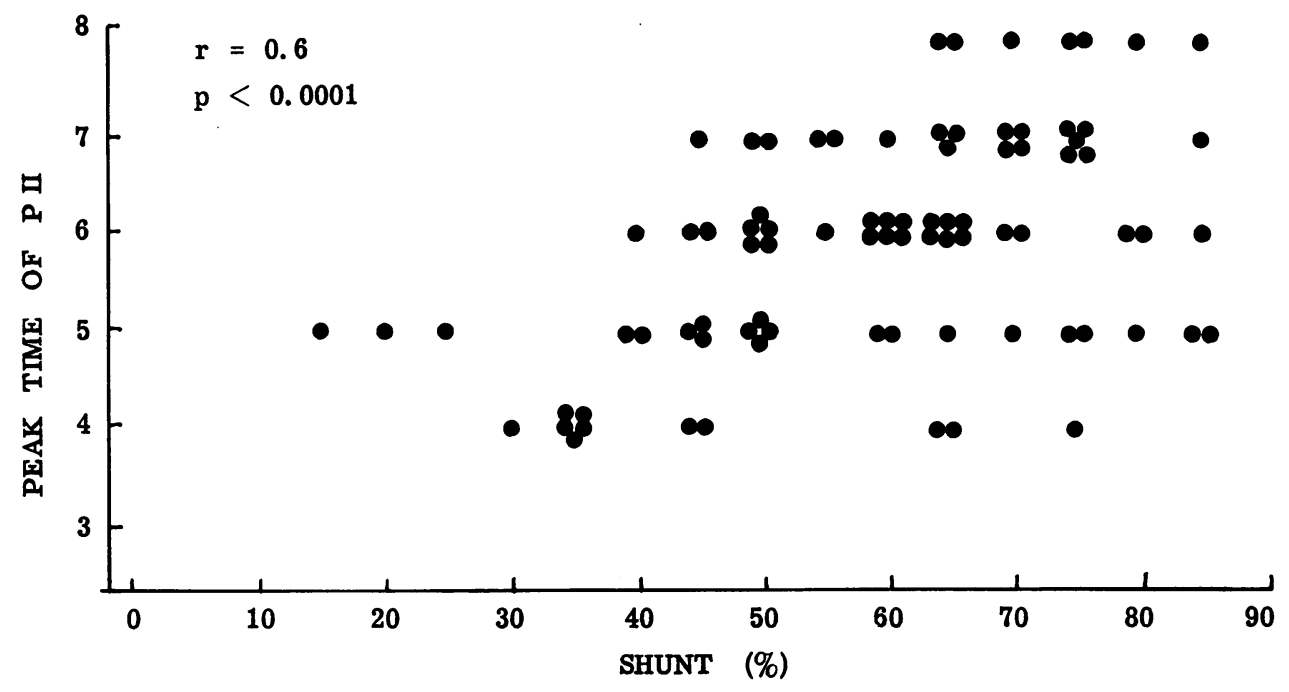

FIG. 2.-The upstroke times (i.e. time from the onset to the peak) of PII in hundredths of a second, found in the 84 cases of the ostium secundum group, plotted against the volume of the left-toright shunt, expressed as a percentage of the pulmonary blood flow.

second, shows a similar correlation with the size of the shunt expressed as a percentage of the pulmonary flow. In Fig. 3 the continuous line represents the line of identity of these values and the broken lines plus or minus 20 per cent of the pulmonary flow. All but $17(20 \%)$ of the cases fall between the \pm 20 per cent lines.

Table V shows the mean values of the hæmodynamic parameters according to the height of PII in the ostium secundum group: no relation is apparent between the height and the volume of the shunt, but the right ventricular systolic pressure is higher in the group with taller $\mathbf{P}$ waves. 


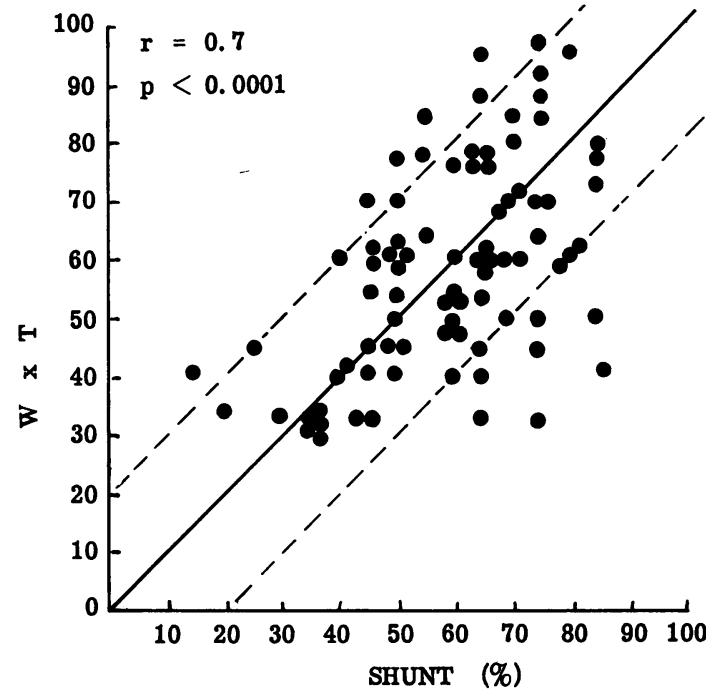

FIG. 3.-The products of the width of PII and the upstroke time, both expressed in hundredths of a second, of the 84 cases in the ostium secundum group, plotted against the volume of the left-to-right shunt, expressed as a percentage of the pulmonary blood flow. The continuous line is the line of identity of these values. The broken lines represent \pm 20 per cent of pulmonary flow.

In $12(14 \%)$ of the ostium secundum group PII showed a notch on its descending limb: this contrasts with an incidence of 45 per cent in the normal subjects and 50 per cent in the ostium primum group. The mean width of PII in the 12 cases with a second peak was $0 \cdot 11$ as compared with 0.095 for the other 72 cases. The upstroke time to the first peak was virtually the same $(0.057$ sec. mean $)$ in these 12 as in the others $(0.059)$ : the mean time from onset to the second peak of PII was $0.10 \mathrm{sec}$. in these cases as compared with $0.06 \mathrm{sec}$. in the normal controls and $0.09 \mathrm{sec}$. in the ostium primum group.

The examination of the $\mathrm{P}$ wave in $\mathrm{V} 1$ revealed a higher incidence of biphasic or negative waves in the ASD cases as compared with the normal subjects (Table VI) but no significant difference between the two ASD groups. The occurrence of biphasic or negative $P$ waves in $V 1$ in the ostium secundum group did not appear to correlate with the size of the shunt or the RV systolic pressure (Table VII) but both atrial, and particularly the left "a" wave pressures, were higher in those with this type of P in V1. Within the ostium secundum group there was a higher incidence of biphasic or negative $\mathrm{P}$ in $\mathrm{V} 1(67 \%)$ in the 12 patients with a second peak in PII than in the others $(40 \%)$ and the mean LA " $a$ " wave pressure was also higher in those 12 patients than in the others $(13 \mathrm{~mm}$. as opposed to $9.7 \mathrm{~mm}$. $\mathrm{Hg})$.

TABLE V

Ostium Secundum Group

Mean Hamodynamic Values According to Height of PII

\begin{tabular}{lll|l|l|l|l|l}
\hline \multicolumn{2}{c|}{ Height } & & No. & Shunt (\%) & RA & LA & RV \\
\hline 2.5 or less & $\ldots$ & $\ldots$ & 72 & 57 & 6.5 & 10 & 44 \\
3.0 or more & $\ldots$ & $\ldots$ & 12 & 69 & 10 & 10 & 55 \\
\hline
\end{tabular}

Abbreviations as in preceding tables.

TABLE VI

FORM OF P IN V1

\begin{tabular}{|c|c|c|c|c|c|}
\hline & & & \multicolumn{3}{|c|}{ Numbers and percentages } \\
\hline & & & \multirow{2}{*}{ Normal } & \multicolumn{2}{|c|}{ ASD } \\
\hline & & & & OS & OP \\
\hline $\begin{array}{l}\text { Positive } \\
\text { Biphasic } \\
\text { Negative }\end{array}$ & $\begin{array}{l}. \\
\cdots \\
\cdots\end{array}$ & $\begin{array}{l}\ldots \\
\ldots \\
\cdots\end{array}$ & $\begin{array}{c}18(90) \\
2(10) \\
0\end{array}$ & $\begin{array}{c}46(55) \\
34(40) \\
4(5)\end{array}$ & $\begin{array}{r}12(55) \\
10(45) \\
0-\end{array}$ \\
\hline
\end{tabular}

Figures in parentheses are percentages.

Abbreviations as in Table I. 
TABLE VII

Ostium Secundum Group

Mean Hemodynamic Values According to Form of P in V1

\begin{tabular}{|c|c|c|c|c|c|c|}
\hline & & No. & $\mathbf{R A}$ & LA & $\mathbf{R V}$ & $\begin{array}{c}\text { Shunt as } \\
\text { percentage }\end{array}$ \\
\hline $\begin{array}{l}\text { Positive .. } \\
\text { Biphasic .. } \\
\text { Negative }\end{array}$ & $\begin{array}{l}\ldots \\
\cdots \\
\cdots\end{array}$ & $\begin{array}{r}46 \\
34 \\
4\end{array}$ & $\begin{array}{l}6 \\
8 \\
9\end{array}$ & $\begin{array}{r}9 \\
11 \\
13\end{array}$ & $\begin{array}{l}42 \\
46 \\
39\end{array}$ & $\begin{array}{l}57 \\
56 \\
65\end{array}$ \\
\hline
\end{tabular}

Abbreviations as in preceding tables.

Records in sinus rhythm were available for 17 of the ostium secundum group obtained a year or more after surgical closure of the defect. The parameters of PII in these patients had all diminished and the mean values in this group post-operatively did not differ significantly from the normal (Table VIII).

TABLE VIII

PARAMETERS OF PII

EfFect of Closure of ASD in 17 Patients

\begin{tabular}{|c|c|c|c|c|}
\hline & & & \multicolumn{2}{|c|}{ Mean values } \\
\hline & & & Before operation & After operation \\
\hline $\begin{array}{l}\text { Height (mm.) } \\
\text { Width (sec.) } \\
\text { Upstroke time (sec.) }\end{array}$ & $\begin{array}{l}\cdots \\
\cdots \\
\cdots\end{array}$ & $\begin{array}{l}\cdots \\
\cdots \\
\cdots\end{array}$ & $\begin{array}{l}2 \cdot 0 \\
0 \cdot 10 \\
0 \cdot 064\end{array}$ & $\begin{array}{l}1 \cdot 0 \\
0.08 \\
0.04\end{array}$ \\
\hline
\end{tabular}

\section{Discussion}

Most of the authors who have studied the electrocardiogram in ASD have concentrated upon the ventricular complex, and little attention has been paid to the $P$ wave. Cabrera (1958) stated that the $P$ wave is normal in 30 per cent of cases of ASD, a little widened in another 30 per cent, and definitely high and wide in the remainder, which he ascribed to biatrial enlargement. Martins de Oliveira and Zimmerman (1958), in their 44 cases, found that cases of ASD with a big interatrial shunt usually have a tall, peaked $P$ wave in the right præcordial leads: only 6 of their cases showed a $P$ wave wider than $0.10 \mathrm{sec}$. They also found slight right axis deviation of the ÂP in cases with a large shunt, and a leftward shift of the ÂP after operation. Toscano Barboza, Brandenburg, and Swan (1958) found features of right atrial enlargement in 36 of their 90 cases and features suggestive of left atrial enlargement in a few more. The $\mathrm{P}$ in V1 was biphasic in $40(45 \%)$, positive in 27 $(20 \%)$, and negative in $23(25 \%)$. Hamer (1960) studied the cardiogram before and after operation in 18 cases of ostium secundum ASD operated upon by the Sondergaard technique. He also measured the upstroke time of the $P$ wave, finding a mean value of $0.06 \mathrm{sec}$. with a range of 0.04 to $0.07 \mathrm{sec}$. before operation: after operation the upstroke time shortened and the mean value was $0.04 \mathrm{sec}$.

In the present series both groups of ASD patients showed greater mean widths of PII than the normal subjects although, according to the normal range for this measurement given by Caceres and Kelser (1959) and Hiss, Lamb, and Allen (1960), even the widest P waves found here could be within normal limits. It is notable that the mean width of PII in the cases of pulmonary stenosis is less than in the ASD cases and also less than in the normal subjects. The correlation found between the width and the shunt volume in the ostium secundum group (Fig. 1) strongly suggests that these differences are significant and that in these patients the width of the PII to some extent reflects the volume load handled by the atria. 
The upstroke time is similarly longer in the two ASD groups than in the normal subjects or in the pulmonary stenosis cases: again the correlation found in the ostium secundum group between this time and the shunt volume (Fig. 2) suggests that these differences are significant and that the upstroke time also reflects the volume load of the atria. The much lower incidence $(14 \%)$ of bifid PII in the ostium secundum group as compared with the normal subjects $(45 \%)$ presumably reflects this longer upstroke time, which means that the first peak (due to the right atrium) is delayed, and so superimposed upon the second (due to the left atrium). Consistent with this view is the higher incidence of bifid waves in the ostium primum group, in which the mean width of PII is even greater than in the secundum group: this is presumably due to coexisting delay in the second peak reflecting further enlargement of the left atrium in the cases where mitral regurgitation is a complicating feature. Furthermore, the ostium secundum cases which had a bifid PII had wider P waves than those which had a single peak, but the upstroke time to the first peak was the same in both: this suggests that the bifid waves in the ostium secundum group were also due to associated delay in the time of second peak, reflecting some coexisting left atrial enlargement.

With the correlations found between the width and upstroke time of PII and the volume of the shunt it appears that the product of these two parameters (expressed in hundredths of a second) has some value in predicting the volume of the left-to-right shunt (expressed as a percentage of pulmonary flow) (Fig. 3). In $25(29 \%)$ the calculated value was within \pm 5 per cent shunt and in another $32(38 \%)$ it was within \pm 15 per cent. While a correlation was found between the width and upstroke time of PII in the ostium secundum group and the volume of the shunt, none was found between these parameters and the pressures measured at cardiac catheterization (Tables III and IV). On the other hand, these patients in whom the height of PII exceeded the normal range (Table V) had higher mean RV systolic pressures: the taller $\mathrm{P}$ waves were also associated with a larger mean shunt volume but the difference is small and may not be significant. The comparison between the ostium secundum group and the pulmonary stenosis patients is instructive. The latter patients have taller $\mathbf{P}$ waves but there is no increase in the upstroke time and the mean width is slightly less than that found in the normal subjects. This pattern of a tall, narrow pointed PII is generally recognized to occur in association with pulmonary stenosis and from the above observations it seems that increased height of PII principally reflects systolic overloading of the right atrium. The correlation between the width and the upstroke time of PII and the volume of the left-to-right shunt into the right atrium and the independence of these parameters and the intracardiac pressures confirm the view (Sánchez-Cascos et al., 1959) that the broad low PII with prolonged upstroke reflects diastolic overloading of the right atrium. The four patients with combined pulmonary stenosis and ASD had high RV systolic pressures and no left-to-right shunts: the principal $P$ wave abnormality in these was the great height of PII with relatively little widening or prolongation of the upstroke. This observation lends support to the view that the $\mathrm{P}$ wave pattern reflects the overloading pattern of the right atrium rather than the anatomical presence of a defect in the septum. Some patients with ASD show tall as well as broad, slow-rising PII and these usually have higher right heart pressures as well as the left-to-right shunt: this type of $P$ wave can be said to reflect systolo-diastolic overloading of the right atrium.

Illustrative records are shown in Fig. 4. The first patient (A) shows the right atrial diastolic overloading pattern. PII is widened $(0.11 \mathrm{sec}$. $)$ and there is a long upstroke time $(0.07 \mathrm{sec}$. $)$ but the height is normal. The product of width and upstroke time is 77 , closely approximating to the shunt determined at catheterization which was 75 per cent of the pulmonary flow. The RV systolic pressure was only $22 \mathrm{~mm}$. Hg. By contrast the second patient (B), one of the four with PS as well as ASD and no left-to-right shunt, shows a very tall narrow PII: this is the pattern of systolic overloading of the RA. The RV systolic pressure was $170 \mathrm{~mm}$. Hg. The third record (C) illustrates systolo-diastolic overloading of the RA with the width $(0.09 \mathrm{sec}$.), the upstroke time $(0.07)$, and the height ( $3 \mathrm{~mm}$.) of PII all increased. In this patient the shunt was 50 per cent of the pulmonary flow and the RV systolic pressure was $72 \mathrm{~mm}$. $\mathrm{Hg}$.

The regression of the three measured parameters of PII towards normal observed in the records 
obtained from 17 of the ostium secundum group a year or more after surgical closure of the defect (Table III) is confirmatory evidence of the significance of the $P$ wave changes described.

Both the ASD groups showed a higher incidence of biphasic or negative $P$ in $V 1$ than was found in the normal subjects (Table VI). In the ostium secundum group there did not appear to be any relation between these patterns and the right ventricular systolic pressure or the volume of the left-to-right shunt. The "a" wave pressures in the two atria are however higher in the patients with these patterns (Table VII). Some of these patients also showed bifid $P$ waves in V6 and it is possible that these patients are exhibiting a pattern of combined (right and left) atrial overload. The fourth case (D) in Fig. 4 illustrates this $\mathrm{P}$ wave pattern. PII is wide $(0.11 \mathrm{sec}$.) with a long upstroke $(0.06 \mathrm{sec}$.) and there is a second peak on its descending limb: $\mathrm{P}$ in $\mathrm{V} 1$ is biphasic and $P$ in V6 is bifid.

The normal bifid PII can be distinguished from these pathological $P$ wave patterns by its rapid upstroke $(0.02-0.03 \mathrm{sec}$.) to the first peak which is widely separated from the second (occurring 0.05-0.07 sec. after the onset); the second peak is rarely taller than the first. In this pattern the $P$ wave is bifid in V3-6 also.

The "mitral" $P$ wave can sometimes resemble the right atrial diastolic overload pattern in lead II when the left atrial peak is not sufficiently delayed to separate it clearly from the right atrial peak, resulting in an apparent prolongation of the upstroke time. In these cases the width of PII is not much increased (SánchezCascos and Herreros, 1961) and the $\mathrm{P}$ waves in the left præcordial leads are clearly bifid.

\section{SUMMARY}

The $\mathbf{P}$ waves in the electrocardiograms from 106 patients with atrial septal defect have been studied and compared with those found in normal subjects and patients with pulmonary stenosis. Of the patients, 84 had ostium secundum or sinus venosus defects, and in this group the correlation of the $\mathbf{P}$ wave pattern and the hæmodynamic changes has been analysed.

The ostium secundum group of ASD patients generally have a slightly wider PII than the normal subjects or the patients with pulmonary stenosis, and the upstroke time is prolonged. Both the width and the upstroke time show statistically significant correlation with the volume of the left-toright shunt: the product of these two measurements has some value in predicting the size of the shunt. This type of $P$ wave was not found in four patients with pulmonary stenosis and ASD in whom there was no L-R shunt. It is concluded that the wide PII with a slow upstroke is the electrocardiographic pattern reflecting diastolic overloading of the right atrium as contrasted with the tall, narrow PII found with pulmonary stenosis, which reflects systolic overloading of the right atrium. 
In patients with ASD and some pulmonary hypertension the $\mathrm{P}$ wave is increased in height as well as showing the above features: this is the pattern reflecting systolo-diastolic overloading.

Nearly half the ASD patients (in both ostium primum and ostium secundum varieties) showed a biphasic $P$ in V1, and many of these also had bifid $P$ waves in V6. It is possible that this reflects some coexisting left atrial enlargement. PII was even wider and more often bifid in the ostium primum group than in the ostium secundum group, and this may be due to a greater degree of left atrial enlargement in these cases because of associated mitral regurgitation.

We would like to acknowledge our indebtedness to our colleagues, medical and technical, too numerous to mention individually, whose labours have provided material for this study. Our thanks are also due to the Department of Medical Illustration, Guy's Hospital, for assistance in preparing the figures.

\section{REFERENCES}

Cabrera, E. (1958). Teoría y Práctica de la Electrocardiografía. La Prensa Médical Méxicana, México. $\longrightarrow$, and Monroy, J. R. (1952). Amer. Heart J., 43, 661 and 669.

Caceres, C. A., and Kelser, G. A. (1959). Amer. J. Cardiol., 3, 449.

Hamer, N. A. J. (1960). Amer. Heart J., 60, 739.

Hiss, R. G., Lamb, L. E., and Allen, M. F. (1960). Amer. J. Cardiol., 6, 200.

Martins de Oliveira, J., and Zimmerman, H. A. (1958). Amer. Heart J., 55, 369.

Sánchez-Cascos, A. (1960). Correlación electrodinámica en las cardiopatías congénitas. Doctoral Thesis, Madrid. - and Herreros, L. (1961). Rev. clín. esp., 83, 427.

- Sokolowski, M., and Rábago, P. de (1959). Rev. clín. esp., 75, 97.

Toscano Barboza, E., Brandenburg, R. O., and Swan, H. J. C. (1958). Amer. J. Cardiol., 2, 698.

Zuckermann, F., Guzmán de la Garza, C., Cisneros, F., and Medrano, G. A. (1952). Arch. Inst. Cardiol. Méx., 22, 550. 